\title{
College Student Perspectives of Telemental Health: a Review of the Recent Literature
}

\author{
Nicole L. Hadler ${ }^{1} \cdot$ Paula Bu $^{2} \cdot$ Aaron Winkler ${ }^{3} \cdot$ Amy W. Alexander $^{3}$ \\ Accepted: 9 December 2020 / Published online: 6 January 2021 \\ (C) The Author(s), under exclusive licence to Springer Science+Business Media, LLC part of Springer Nature 2021
}

\begin{abstract}
Purpose of Review We review the recent literature regarding college student experiences with and attitudes toward telemental health (TMH). We examine their perspectives of the advantages and drawbacks to this form of mental healthcare and their willingness to engage in TMH.

Recent Findings College students view TMH as convenient, accessible, easy to use, and helpful. TMH helps to overcome the barrier of stigma associated with seeking mental health treatment. Despite positive reviews, many students find a lack of customization or connection to the provider to be drawbacks to some forms of TMH. Willingness to engage in TMH varies based on prior experience with mental health treatment, ethnicity, and severity of symptoms.

Summary The recent literature highlights the potential for TMH to play a key role in mental health services for college students. It also highlights some of its shortcomings, which are indicative of the continued need for in-person services. Future studies should continue to track college student perspectives toward and utilization of TMH.
\end{abstract}

Keywords Telemental health $\cdot$ Telepsychiatry $\cdot$ Telehealth $\cdot$ College student $\cdot$ University $\cdot$ College counseling

\section{Introduction}

Telemental health $(\mathrm{TMH})$ refers to mental healthcare that is provided remotely via electronic device. For the purposes of this article, TMH will encompass internet-based interventions, video or phone calls with a mental healthcare provider, and applications (which will be referred to as "apps" in this article) used on phones or tablets. TMH has been around for over six decades, with one of the first documented uses for group therapy and consult-liaison psychiatry at the Nebraska Psychiatric Institute in 1959 [1]. It continues to evolve with the advent of

This article is part of the Topical Collection on Complex MedicalPsychiatric Issues

Nicole L. Hadler

hadlernl@umich.edu

1 University of Michigan Medical School, 1301 Catherine Street, Ann Arbor, MI 48109, USA

2 Department of Psychiatry, Icahn School of Medicine at Mount Sinai, New York, NY, USA

3 Department of Psychiatry \& Behavioral Sciences, Stanford University School of Medicine, Stanford, CA, USA new technologies and has been increasingly used as a means to deliver mental healthcare, especially for those who are isolated or live in rural areas [1]. Over the years, TMH has expanded to encompass one-on-one counseling, psychopharmacologic management, robotic platforms, and a wide array of phone apps addressing mental health concerns, ranging from stress relief to drinking cessation.

One population in particular for which $\mathrm{TMH}$ has expanded is college students in the USA. Compared to $10 \%$ of colleges in 2016, 59\% of colleges in 2018 reported offering $\mathrm{TMH}$ services [2]. TMH has in part addressed the growing need for mental health services on college campuses, which has been increasingly recognized. Between 2007 and 2017, the rate of mental health treatment among college students increased from 19 to $34 \%$ [3••]. In the 2018 annual survey from the Association for the University and College Counseling Center Directors (AUCCCD), over half of college directors reported that they needed more hours of psychiatric services than they currently had to meet student needs [4•]. Furthermore, university presidents have expressed needing more tools providing assessment and coping strategies to address mental health concerns in this population.

Studies have shown that TMH can effectively treat depression $[5,6]$, anxiety [5, 6], sleep [7], stress [8, 9], alcohol use 
disorders [10-13], PTSD [14, 15], and eating disorders [6, 16] in college students. It has been used by college students through a variety of platforms, including, but not limited to, phone apps, online modules, and text messaging $[17,18]$.

In light of the COVID-19 pandemic starting December 2019, TMH has been especially pertinent given the risks of in-person visits to patients and providers. Never has there been a more rapid shift toward telehealth. With universities sending students home and transitioning to online learning, many college students have struggled to adapt to this new reality [19••]. Further complicating this problem are licensing restrictions for medical providers and psychotherapists in providing medical care and psychotherapy across state lines [20, 21]. According to a survey of 2086 college students in April $2020,80 \%$ of college students reported that COVID-19 has negatively affected their mental health, and $85 \%$ endorsed difficulty with focusing on school and work [19••]. More than half of students $(55 \%)$ reported that they would not know where to go if they or someone they knew needed professional mental health services right away $[19 \bullet \bullet]$.

TMH has the potential not only to deliver the care needed by college students during these unprecedented times but also to play a prominent role in serving this population going forward. It is important to assess their opinions about this form of healthcare in order to most effectively guide future interventions, funding, and resource allocation on college campuses. In this article, we review the recent literature to better understand the attitudes of college students across the USA toward TMH services in the context of their unique perspectives, experiences, and struggles.

\section{Perceived Advantages of TMH}

Cohen et al. categorized barriers noted by college students seeking mental health services as structural and psychological [22]. Structural barriers, according to this study as well as others [23-25], include appointment times conflicting with their schedules or not aligning with the time of acute need. Students also noted the presence of waitlists, inconvenient or unknown location of mental health services, and financial burden as concerns [22]. Psychological barriers include the stigma surrounding mental health treatment, preference to handle their symptoms alone, discomfort with opening up to a therapist, and lack of motivation to seek treatment $[22,25,26]$. College students report that TMH overcomes both structural and psychological barriers.

Students view TMH services as convenient and flexible. Without concern for coordinating schedules, waitlists, or traveling to a clinic, college student participants in TMH studies have found electronic support to be consistently accessible and available at their convenience [27-30]. In addition, college students note easier access to previously discussed materials as a potential advantage of TMH [30]. There is also the potential benefit of avoiding the costs of transportation, childcare, or missed work to attend in-person appointments.

Studies of TMH in college students consistently note satisfaction among participants concerning usability of the service. Over $90 \%$ of college students use the Internet daily [18], and approximately $86 \%$ of college students use a smart phone regularly [31]. Not surprisingly, students report convenience, acceptability, and usability of mobile phone apps for mental health interventions, including those for mindfulness, drinking cessation, depression, and anxiety [32-36]. Students also report that internet-delivered cognitive behavioral therapy (CBT) is easy to use [27, 36, 37].

Student participants across a variety of TMH studies consistently describe a high level of satisfaction with their experience. This includes satisfaction with automated messaging platforms $[38,39]$ and self-directed therapy modules $[9,36,37]$. Participants in mindfulness app interventions reported that they found the mindfulness exercises to be helpful [40], as did participants in psychoeducation and mindfulness video sessions [41] and internet-based CBT $[27,36,37]$. Students found a webbased acceptance and commitment therapy (ACT) program, a type of CBT proven to treat a wide range of psychiatric illnesses [42], to be helpful for those in counseling, and they would recommend the program to others who are distressed or are currently in counseling [37, 43]. In addition, not only have students found TMH to be helpful during the study, but many also report applicability and continued use of the TMH intervention after the study. For example, nearly all of the participants in a web-based stress management intervention reported that they applied what they learned to their everyday lives, though notably this was within 3 weeks after completion of the program [44].

Furthermore, TMH services offer opportunities for college students to avoid the stigma of seeking mental health treatment. This is an obstacle particularly for minority students [23], who are less likely than Caucasian students to utilize mental health services despite experiencing similar or elevated rates of markers of mental illness such as suicidality, suicide attempt, or self-harm $[45,46]$. One possible explanation for underutilization of mental healthcare by ethnic minority students is that they are more likely to perceive negative judgment from family, friends, and others as a treatment barrier than are their Caucasian peers $[23,47]$. One particular TMH intervention, Kognito, is a virtual program for students and faculty that trains participants in suicide prevention through a series of simulated human animations [48]. After undergoing the training, not only did participants feel better able to identify and assist people at risk of suicide, but they also reported increased willingness to seek treatment for themselves [49]. TMH can also provide college students a sense of ownership over their psychological struggles. Students noted feeling in control of the pace of the intervention [27] and appreciated the casual nature in which they could receive help compared to if they were to seek help at a counseling center [28]. 


\section{Perceived Disadvantages of TMH}

Even though college students note benefits of TMH and report high levels of satisfaction, the literature on college student preferences for in-person or TMH is mixed, with a preponderance of studies suggesting that students still tend to prefer face-to-face mental health care, citing feelings of discomfort or unfamiliarity with TMH, privacy concerns, and lack of personalization as drawbacks.

In an online survey administered to 662 college students in Indiana, $68 \%$ of respondents said they would prefer to speak to someone in person about their mental health concerns [50]. Only $17 \%$ expressed preferences for text or online chat, and even fewer preferred phone or video calls. Additionally, they expressed feeling more comfortable meeting with a therapist in-person rather than online. In another survey of 500 college students, $93 \%$ said they would prefer face-to-face therapy rather than video conferencing or other virtual counseling [51]. Similarly, in a smaller survey study of 41 undergraduate students, $88 \%(n=37)$ expressed a preference for face-to-face mental health counseling [52]. $61 \%(n=25)$ indicated that they would most likely not use TMH counseling if it were available at their college, though it was thought that this could partially be attributed to lack of familiarity with TMH. An open, non-randomized trial in 2018 in which 102 undergraduates received internet-based CBT found that despite positive reviews of the platform, the majority of participants would have preferred in-person therapy [27].

A common theme that emerged among students who expressed a preference for face-to-face care, as well as among students in general when asked to provide feedback on their TMH experience, was a desire for more personalized advice and care. Among 270 college students who were actively receiving mental health counseling through their school, $67 \%$ expressed concern about a lack of personalization and/or compromise to the therapeutic relationship with TMH compared to in-person counseling [30]. This concern was also noted among participants in studies of therapy-based applications as well as apps that targeted more specific areas such as drinking. A number of TMH apps have been trialed, each with varying levels of feedback for participants incorporated into their program. In the small feasibility trial of internetdelivered CBT programs for depression, anxiety, and stress, participants brought up lack of tailoring and interactive features of the therapy as areas for improvement [27]. Each participant in this study was assigned a licensed social worker or psychologist as his or her supporter; supporters were responsible for providing written weekly feedback based on a review of the participant's progress. The majority $(11 / 14,79 \%)$ of the participants in the study's structured post-intervention interview would have liked more involvement from the supporter. Participants specifically wanted more detailed and personalized feedback and felt like they lacked a connection with the supporter. Some participants would have liked to be able to speak directly with their supporter over the phone or video chat service rather than receiving feedback in writing.

Similarly, participants in the Smartrek drinking app study enjoyed the "coach" feature, which sent daily text messages and reminders to promote healthier drinking habits, but they also would have liked for the coach to be more interactive throughout their TMH experience [33]. Furthermore, participants in a web-based stress reduction intervention also would have liked personalized messages for their exercises [40].

Another therapy-based intervention is the use of robotic platforms, including the study of a platform called "Woebot" which uses automated text messaging to deliver CBT to college students who endorsed symptoms of depression and/or anxiety [38]. Strengths noted by several college student participants included the bot's empathy and "personality." In fact, many participants started referring to the bot using human terms such as "little dude" and "friend." Though this suggested that a therapeutic relationship had been established between the bot and some of the participants, a common complaint was disruptions in natural conversation, especially if the bot did not understand a participant's response. Some participants also reported that their conversations felt too short. Less frequent feedback included technical glitches [38]. Other drawbacks to TMH noted by college students include programs that were too long or repetitive, lack of time, lack of privacy, and dislike for the web-based self-help format in general [37].

Though TMH has the potential to lessen the barrier of stigma of mental health help seeking among college students, perceived stigma may not completely resolve regardless of mental health treatment platform. For example, one-third of youth reported that they would feel concerned about judgment from others if they were to call the National Suicide Prevention Hotline [53]. Furthermore, stigma is correlated with a lower level of perceived value and higher level of discomfort among students toward not only face-to-face mental health treatment but also TMH [51].

There is some literature conveying the opposite: that students may prefer TMH to face-to-face mental healthcare. A survey study of 572 college students reported a greater willingness to seek help online (75\%) than face-to-face (63\%) for emotional problems [54]. However, they also reported being less likely to disclose personal information online, with $64 \%$ of participants reporting that they would disclose less information online compared to in-person. Reasons for this lower likelihood of disclosure were not elicited from participants, but it was suggested that different online platforms might have varying levels of perceived trustworthiness. Of note, participants in this study were predominantly Asian students and in school on the West Coast, while the studies describing a preference for in-person care consisted of predominantly Caucasian participants in the Midwest $[27,50]$ or Southeastern USA [52]. 


\section{Student Willingness to Try TMH}

Willingness of distressed college students to use TMH services is lower than their willingness to use in-person mental healthcare, with the majority of students feeling it would be easier to speak with a professional face-to-face [29]. Nonetheless, many college students are open to utilizing TMH services, and their willingness to use varies depending on a number of factors. Factors that correlate with openness to TMH include prior in-person treatment, severity of the mental health condition, type of TMH intervention, purpose of the service, level of social support, and gender [29, 50, 55, 56].

Dunbar et al. found that compared to students with no prior in-person treatment, students with prior in-person treatment were more likely to feel that receiving in-person treatment would be easier and more comfortable. However, there was no significant difference in willingness to try TMH [29]. Toscos et al. found that students with more severe forms of mental illness were more willing to use TMH [50]. For example, compared to students with low-scoring levels of depression or anxiety, those with higher scores were more willing to use anonymous online chats and self-help resources. In addition, students with higher stress levels were more willing to engage in self-help resources, as were women compared to men [50]. Students also reported varied willingness to use TMH depending on the specific service offered; $40 \%$ expressed interest in self-help resources, $29 \%$ expressed interest in using an online therapist, and $25 \%$ were interested in anonymous online chats. Women and those with higher stress were more likely to express interest in using self-help resources [50]. Ruppel et al. found that while students with a higher level of social support acknowledge the benefits of online mental health resources, they were less likely to visit websites for mental or emotional help [55]. Meanwhile, those with a lower level of social support were more likely to visit websites for help.

Additionally, concerning hotline utilization, college students are willing to use the National Suicide Prevention Lifeline (NSPL), with 50\% or more of students reporting they would be likely to use the hotline in the setting of suicidal symptoms. However, the reported likelihood of using the hotline was lower than the students' perceived helpfulness of this resource [56]. Additionally, college students' comments suggested that they may be more willing to use the suicide hotline for someone else than for themselves [56].

In another survey of college students regarding mental health apps, $26 \%$ responded "yes" to being open to using an app [57]. Only $13 \%$, however, thought that such apps were evidence-based. It is important to note that in this study, only $7 \%$ of participants had ever used a mental health app. In addition, the most common reason for students being uninterested in using this resource was due to not having a mental health concern. Increased willingness to use a mental health app was found among younger participants, females, and participants who had received mental health treatment within the past year [57].

\section{Student Willingness to Follow Through with TMH Care}

Studies have found differing levels of completion and followup during trials of TMH services with college students. Bernstein et al. experienced a $92 \%$ retention rate of students in their text message intervention study aimed at reducing alcohol consumption, based on completion of a follow-up survey the day after their 21st birthday [58]. Meanwhile, Palacios et al. found that the student participants only completed an average of $50 \%$ of the internet-based CBT content over the course of 8 weeks [27]. Some students reported a lack of motivation to finish the weekly sessions, with several reporting feeling less accountable for online tasks than those done in-person [27]. In a randomized controlled trial for a therapist-assisted web-based program for anxiety, despite a high level of interest in the program, which was reflected by inability of the study to accommodate all interested students, one-third of the participants in the treatment group never opened any of the sessions [41].

In addition, rates of completion of multi-session TMH interventions tended to decline with each subsequent session, with $30-57 \%$ of participants completing all of the program's sessions [13, 37, 41, 43, 59]. Despite many studies offering compensation to students for completion of some or all of the sessions, including extra credit $[18,37,44,55,60]$ or monetary compensation $[17,38,61,62]$, retention was still low. For example, in an alcohol intervention program offering a total of $\$ 30$ compensation for approximately $1 \mathrm{~h}$ of time, only about half of the students completed each follow-up. Males and heavy drinkers were less likely to complete the follow-ups [62].

Participants suggested email reminders as a potential means of improving completion rates [27]. The text message intervention survey that experienced a $92 \%$ retention rate provided four reminders to participants who did not initially respond to the survey: one email, two text messages, and one phone call [58]. 85\% of participants in a mindfulness app study noted that text messages were helpful reminders to practice mindfulness [63]. Students appreciated the "accountability from daily check-ins" from a robotic platform as well [38].

Poor treatment adherence and follow-up among college students is prevalent in in-person mental healthcare as well. For example, less than half of the college students receiving support at a counseling center followed through with treatment recommendations from the counseling center for further counseling or a referral [23]. Total treatment barriers, which included items such as financial concerns, stigma, and 
preference to deal with problems on one's own, were associated with lower likelihood of following through with recommendations [23]. Meanwhile, provision of adequate assistance, such as with setting up follow-up appointments, was associated with over five times greater odds of following through with provider recommendations [23]. To our knowledge, there is no literature directly comparing attrition and reasons for dropout for in-person versus virtual mental healthcare. However, one hypothesis is that a loss of human connection in virtual care may lessen feelings of accountability for students to follow through with care [38]. Also, given that many of these studies included asymptomatic participants, it is possible that students did not resonate with the content which contributed to a lack of motivation to follow through with the intervention.

\section{Conclusions}

The transition to telehealth has been inevitable in the COVID19 era, including the transition to TMH services among college students. It will continue to play a large role in the foreseeable future, making it especially important to understand college student perceptions of these electronic platforms for mental healthcare. There are a wide array of TMH platforms for college students, including mobile phone apps, text messaging, online programs, hotlines, and video visits. Though the literature is sparse concerning college student opinions of live, one-on-one video, or phone visits with a therapist or psychiatrist, there is literature highlighting their views of the other TMH platforms, which have been described in detail in this report.

College students find TMH to be convenient, accessible, easy to use, and helpful. TMH also helps to overcome the barrier of stigma, which may help ethnic minority students in particular to seek care. However, students with access to technology and the internet may have been over-represented in many of these studies, given the nature of recruitment and the study designs themselves. It is important to note that limited access to technology and the internet has been highlighted as potential drawbacks to TMH $[64,65]$.

The most commonly noted drawback of TMH by college students was a desire for more personalized care and interactions with the provider. Even when students were assigned a personal "coach" or supporter who communicated with them during the program, they sought more customization of internet-based and app-based therapy to suit their personal needs. The lack of connection to their supporter or provider could be partially attributed to the specific platforms of these interventions; communication was via text message or online chatting rather than face-to-face. Literature discussing college student opinions about the level of personalization and connection experienced during one-on-one care via phone call or video is lacking.

Inadequate customization of TMH services may also be one of the factors contributing to the high attrition rates in these studies. Participants had poor follow through with even brief interventions despite reminders and incentives. It is important to note that acute psychiatric symptoms were not part of the inclusion criteria for these studies, so it would be useful to evaluate attrition among participants who are specifically symptomatic and in need of mental health interventions.

Student preferences for and willingness to use in-person or telemental health care vary based on prior experience with mental healthcare, ethnicity, and severity of mental illness. Participants with no prior counseling use were less likely than those who had received counseling in the past to be willing to try a remote form of counseling. This suggests the need for increased awareness of and experience with TMH to improve student perceptions of and willingness to use this form of mental healthcare. Awareness of TMH will likely continue to improve with time throughout the COVID-19 pandemic and thereafter as remote healthcare continues to become more prevalent. Ethnicity may also play a role in preference for inperson or remote care. For example, one study of predominantly Asian students on the West Coast showed preferences for remote TMH [54], while the studies describing preferences for in-person care consisted of predominantly Caucasian participants in the Midwest [27, 50] or Southeast [52]. These findings are in line with other literature previously discussed that stigma is a stronger barrier to mental healthcare seeking among minority students, though this cannot be generalized here given the low quantity of TMH literature. It would be helpful to further elucidate the roles that ethnicity and geographic location play in preferences for online versus inperson mental health treatment among college students.

Furthermore, patients with more severe mental health symptoms, including higher levels of depression, anxiety, and stress, were more willing to use TMH than those with less severe symptoms. It is logical that those with a higher symptom burden would be more likely to seek any form of care due to higher levels of distress and/or functional impairment from these symptoms. However, students with more severe psychiatric symptoms are also more likely to be higher risk patients. This poses a potential safety and liability concern; it would be in the best interest of these students if there were a screening process in place that would bring high-risk students to the attention of providers so that they can be brought in for a more depth, in-person evaluation.

The American College Health Association (ACHA), which conducts a biannual survey to assess the overall health of college students, wrote a new survey for the fall of 2020 , which now incorporates the term "telehealth" in questions related to seeking medical care and includes questions related to the COVID-19 pandemic [66]. Though this terminology 
acknowledges the growing use of virtual healthcare, the updated questions do not specifically elicit college student experiences with telehealth to include TMH. Incorporation of $\mathrm{TMH}$ in future ACHA biannual surveys would allow colleges to better understand student utilization and perspectives of this form of mental healthcare delivery and guide colleges as they continue to adapt to telehealth.

$\mathrm{TMH}$ has the potential to play a prominent role in serving the college student population going forward, making it important to understand their opinions in order to most effectively guide future interventions. While students note several advantages including convenience and less fear of stigma, there are potential drawbacks related to personalization and attrition. The extent of these drawbacks for college students may be different for face-to-face video visits or one-on-one phone calls, but this needs to be further assessed given the paucity of literature looking into these drawbacks specifically. In the meantime, while TMH continues to evolve and improve, TMH may be more appropriate as a complement to inperson care for college students rather than a replacement, especially in students with more severe psychiatric illness.

Acknowledgements The editors would like to thank Dr. Meera Menon for taking the time to review this manuscript.

\section{Compliance with Ethics Standrads}

Conflict of Interest The authors declare that they have no conflicts of interest.

Human and Animal Rights and Informed Consent This article does not contain any studies with human or animal subjects performed by any of the authors.

\section{References}

Papers of particular interest, published recently, have been highlighted as:

- Of importance

•- Of major importance

1. Liebson, E. Telepsychiatry: thirty-five years' experience. Medscape Psych \& Mental Health E Journal. 1997;2(4). https://www. medscape.com/viewarticle/431064_4.

2. LeViness P, Bershad C, Gorman K, Braun L, Murray T. The Association for University and College Counseling Center Directors Annual Survey. AUCCCD. 2018. https://www.aucced. org/assets/documents/Survey/2018\%20AUCCCD\%20SurveyPublic-June\%2012-FINAL.pdf. .

3.• Lipson SK, Lattie EG, Eisenberg D. Increased rates of mental health service utilization by U.S. college students: 10-year population-level trends (2007-2017). Psychiatr Serv. 2019;70(1):60-63. doi:https://doi.org/10.1176/appi.ps.201800332. This study offers the most recent comprehensive review of mental health usage over the span of a decade, highlighting the upward trend in mental health service utilization among college students.
4. LeViness P, Gorman K, Braun L, Koenig L, Bershad C. The Association for University and College Counseling Center Directors Annual Survey. AUCCCD. 2019. https://www.aucced. org/assets/documents/Survey/2019\%20AUCCCD\%20Survey2020-05-31-PUBLIC.pdf. Accessed December 3, 2020. This annual survey of college counseling center directors offers the most up-to-date overview of staffing and resources provided by college counseling centers, and it found an increased demand for counseling services in the past year.

5. Bolinski F, Boumparis N, Kleiboer A, Cuijpers P, Ebert DD, Riper $H$. The effect of e-mental health interventions on academic performance in university and college students: a meta-analysis of randomized controlled trials. Internet Interv. 2020 Apr 23;20:100321. doi: https://doi.org/10.1016/j.invent.2020.100321.

6. Harrer M, Adam SH, Baumeister H, Cuijpers P, Karyotaki E, Auerbach RP, et al. Internet interventions for mental health in university students: a systematic review and meta-analysis. Int $\mathrm{J}$ Methods Psychiatr Res. 2019 Jun;28(2):e1759. https://doi.org/10. 1002/mpr.1759.

7. Gipson CS, Chilton JM, Dickerson SS, Alfred D, Haas BK. Effects of a sleep hygiene text message intervention on sleep in college students. J Am Coll Heal. 2019;67(1):32-41. https://doi.org/10. 1080/07448481.2018.1462816.

8. Huberty J, Green J, Glissmann C, Larkey L, Puzia M, Lee C. Efficacy of the mindfulness meditation mobile app "calm" to reduce stress among college students: randomized controlled trial. JMIR Mhealth Uhealth. 2019 Jun 25;7(6):e14273. https://doi.org/10. 2196/14273.

9. Harrer M, Adam SH, Fleischmann RJ, Baumeister H, Auerbach R, Bruffaerts R, et al. Effectiveness of an internet- and app- based intervention for college students with elevated stress: randomized controlled trial. J Med Internet Res. 2018 Dec 23;20(4):e136. https://doi.org/10.2196/jmir.9293.

10. Paschall MJ, Antin T, Ringwalt CL, Saltz RF. Evaluation of an internet-based alcohol misuse prevention course for college freshmen: findings of a randomized multi-campus trial. Am J Prev Med. 2011;41(3):300-8. https://doi.org/10.1016/j.amepre. 2011.03.021.

11. Hennessy EA, Tanner-Smith EE, Mavridis D, Grant SP. Comparative effectiveness of brief alcohol interventions for college students: results from a network meta-analysis. Prev Sci. 2019;20(5):715-40. https://doi.org/10.1007/s11121-018-0960-z.

12. Prosser T, Gee KA, Jones F. A meta-analysis of effectiveness of einterventions to reduce alcohol consumption in college and university students. J Am Coll Heal. 2018;66(4):292-301. https://doi.org/ 10.1080/07448481.2018.1440579.

13. King SC, Richner KA, Tuliao AP, Kennedy JL, McChargue DE. A comparison between telehealth and face-to-face delivery of a brief alcohol intervention for college students. Subst Abus. 2019 Oct;23: 1-9. https://doi.org/10.1080/08897077.2019.1675116.

14. Miner A, Kuhn E, Hoffman JE, Owen JE, Ruzek JI, Taylor CB. Feasibility, acceptability, and potential efficacy of the PTSD Coach app: a pilot randomized controlled trial with community trauma survivors. Psychol Trauma Theory Res Pract Policy. 2016;8(3): 384-92 http://search.ebscohost.com.proxy.lib.umich.edu/ login. asp $x$ ?direct $=$ true $\& d b=$ psyh $\& A N=2016-03896$ 001\&site $=$ ehost-live $\&$ scope $=$ site .

15. Possemato K, Kuhn E, Johnson E, Hoffman JE, Owen JE, Kanuri $\mathrm{N}$, et al. Using PTSD Coach in primary care with and without clinician support: a pilot randomized controlled trial. Gen Hosp Psychiatry. 2016 Jan-Feb;38:94-8. https://doi.org/10.1016/j. genhosppsych.2015.09.005.

16. Lipson SK, Jones JM, Taylor CB, Wilfley DE, Eichen DM, Fitzsimmons-Craft EE, et al. Understanding and promoting treatment-seeking for eating disorders and body image concerns on college campuses through online screening, prevention and 
intervention. Eat Behav. 2017 Apr;25:68-73. https://doi.org/10. 1016/j.eatbeh.2016.03.020.

17. Lui JHL, Marcus DK, Barry CT. Evidence-based apps? A review of mental health mobile applications in a psychotherapy context. Prof Psychol Res Pract. 2017;48(3):199-210. https://doi.org/10.1037/ pro0000122.

18. Nguyen-Feng VN, Greer CS, Frazier P. Using online interventions to deliver college student mental health resources: evidence from randomized clinical trials. Psychol Serv. 2017 Nov;14(4):481-9. https://doi.org/10.1037/ser0000154.

19.• Young Adult Mental Health Survey. Active Minds. 2020. www. activeminds.org/studentsurvey. Accessed December 3, 2020. This survey of over 2000 college students draws attention to worsening mental health symptoms and lack of knowledge regarding help services among college students in the setting of COVID-19.

20. The University of Texas at Austin Counseling and Mental Health Center. State-by-state guide telehealth. 2020. https://cmhc.utexas. edu/state telehealth.html. Accessed December 2, 2020.

21. Federation of State and Medical Boards. U.S. states and territories modifying requirements for telehealth in response to COVID-19. 2020. https://www.fsmb.org/siteassets/advocacy/pdf/stateswaiving-licensure-requirements-for-telehealth-in-response-tocovid-19.pdf. Accessed December 2, 2020.

22. Cohen KA, Graham AK, Lattie EG. Aligning students and counseling centers on student mental health needs and treatment resources. J Am Coll Heal. 2020 May;20:1-9. https://doi.org/10.1080/ 07448481.2020 .1762611$.

23. Miranda R, Soffer A, Polanco-Roman L, Wheeler A, Moore A. Mental health treatment barriers among racial/ethnic minority versus white young adults 6 months after intake at a college counseling center. J Am Coll Heal. 2015;63(5):291-8. https://doi.org/10.1080/ 07448481.2015.1015024.

24. Shea M, Wong YJ, Nguyen KK, Gonzalez PD. College students' barriers to seeking mental health counseling: scale development and psychometric evaluation. J Couns Psychol. 2019 Oct;66(5):62639. https://doi.org/10.1037/cou0000356.

25. Ebert DD, Mortier P, Kaehlke F, Bruffaerts R, Baumeister H, Auerbach RP, et al; WHO World Mental Health-International College Student Initiative collaborators. Barriers of mental health treatment utilization among first-year college students: first crossnational results from the WHO World Mental Health International College Student Initiative. Int J Methods Psychiatr Res. 2019 Jun;28(2):e1782. doi: https://doi.org/10.1002/mpr.1782. Epub 2019 May 9. Erratum in: Int J Methods Psychiatr Res. 2019 Dec; 28(4):e1800. This large-scale, international survey study highlights the barriers to seeking mental health treatment among college students, including the influence of stigma.

26. Montagni I, Tzourio C, Cousin T, Sagara JA, Bada-Alonzi J, Horgan A. Mental health-related digital use by university students: a systematic review. Telemed J E Health. 2020 Feb;26(2):131-46. https://doi.org/10.1089/tmj.2018.0316.

27. Palacios JE, Richards D, Palmer R, Coudray C, Hofmann SG, Palmieri PA, et al. Supported internet-delivered cognitive behavioral therapy programs for depression, anxiety, and stress in university students: open, non-randomised trial of acceptability, effectiveness, and satisfaction. JMIR Ment Health. 2018 Dec 14;5(4):e11467. https://doi.org/10.2196/11467.

28. Park SY, Andalibi N, Zou Y, Ambulkar S, Huh-Yoo J. Understanding students' mental well-being challenges on a university campus: interview study. JMIR Form Res. 2020 Mar 5;4(3): e15962. https://doi.org/10.2196/15962.

29. Dunbar MS, Sontag-Padilla L, Kase CA, Seelam R, Stein BD. Unmet mental health treatment need and attitudes toward online mental health services among community college students.
Psychiatr Serv. 2018;69(5):597-600. https://doi.org/10.1176/appi. ps.201700402.

30. Petersen D, Salazar B, Kertz SJ. Therapist and treatment-seeking students' perceptions of telemental health. J Technol Behav Sci. 2019 Nov 22;5:113-20. https://doi.org/10.1007/s41347-01900116-8.

31. Poll H. National report: college students. Pearson Student Mobile Device Survey. 2015; https://www.pearsoned.com/wp-content/ uploads/2015-Pearson-Student-Mobile-Device-Survey-College. pdf.

32. Carey TA, Haviland J, Tai SJ, Vanags T, Mansell W. MindSurf: a pilot study to assess the usability and acceptability of a smartphone app designed to promote contentment, wellbeing, and goal achievement. BMC Psychiatry. 2016 Dec 12;16(1):442. https://doi.org/10. 1186/s12888-016-1168-Z.

33. Kazemi DM, Borsari B, Levine MJ, Shehab M, Nelson M, Dooley $\mathrm{B}$, et al. Real-time demonstration of a mHealth app designed to reduce college students hazardous drinking. Psychol Serv. 2019 May;16(2):255-9. https://doi.org/10.1037/ser0000310.

34. Levin ME, Hicks ET, Krafft J. Pilot evaluation of the stop, breathe $\&$ think mindfulness app for student clients on a college counseling center waitlist. J Am Coll Heal. 2020 Mar;9:1-9. https://doi.org/10. 1080/07448481.2020.1728281.

35. Haeger JA, Davis CH, Levin ME. Utilizing ACT daily as a selfguided app for clients waiting for services at a college counseling center: a pilot study. J Am Coll Heal. 2020 Jun;12:1-8. https://doi. org/10.1080/07448481.2020.1763366.

36. Melnyk BM, Amaya M, Szalacha LA, Hoying J, Taylor T, Bowersox K. Feasibility, acceptability, and preliminary effects of the COPE online cognitive-behavioral skill-building program on mental health outcomes and academic performance in freshmen college students: a randomized controlled pilot study. J Child Adolesc Psychiatr Nurs. 2015 Aug;28(3):147-54. https://doi.org/ 10.1111/jcap.12119.

37. Levin ME, Haeger JA, Pierce BG, Twohig MP. Web-based acceptance and commitment therapy for mental health problems in college students: a randomized controlled trial. Behav Modif. 2017 Jan 1;41(1):141-62. https://doi.org/10.1177/0145445516659645.

38. Fitzpatrick KK, Darcy A, Vierhile M. Delivering cognitive behavior therapy to young adults with symptoms of depression and anxiety using a fully automated conversational agent (Woebot): a randomized controlled trial. JMIR Ment Health. 2017 Jun 6;4(2):e19. https://doi.org/10.2196/mental.7785.

39. Fulmer R, Joerin A, Gentile B, Lakerink L, Rauws M. Using psychological artificial intelligence (Tess) to relieve symptoms of depression and anxiety: randomized controlled trial. JMIR Ment Health. 2018 Dec 13;5(4):e64. https://doi.org/10.2196/mental. 9782.

40. Greer C. An online mindfulness intervention to reduce stress and anxiety among college students. Vol. 77, Dissertation Abstracts International: Section B: The Sciences and Engineering. ProQuest Information \& Learning. 2016. http://search.ebscohost.com.proxy. lib.umich.edu/login.aspx?direct $=$ true $\& d b=$ psyh $\& A N=2016$ 37853-163\&site=ehost-live \&scope $=$ site.

41. Eustis EH, Hayes-Skelton SA, Orsillo SM, Roemer L. Surviving and thriving during stress: a randomized clinical trial comparing a brief web-based therapist-assisted acceptance-based behavioral intervention versus waitlist control for college students. Behav Ther. 2018;49(6):889-903. https://doi.org/10.1016/j.beth.2018.05.009.

42. Ruiz FJ. A review of acceptance and commitment therapy (ACT) empirical evidence: correlational, experimental psychopathology, component and outcome studies. International Journal of Psychology \& Psychological Therapy. 2010;10(1):125-62 http:// search.ebscohost.com.proxy.lib.umich.edu/login.aspx?direct= true $\& \mathrm{db}=$ psyh $\& \mathrm{AN}=2010-05335-008 \&$ site $=$ ehost-live $\&$ scope $=$ site. 
43. Levin ME, Pistorello J, Hayes SC, Seeley JR, Levin C. Feasibility of an acceptance and commitment therapy adjunctive web-based program for counseling centers. J Couns Psychol. 2015 Jul;62(3): 529-36. https://doi.org/10.1037/cou0000083.

44. Frazier P, Meredith L, Greer C, Paulsen JA, Howard K, Dietz LR, et al. Randomized controlled trial evaluating the effectiveness of a web-based stress management program among community college students. Anxiety Stress Coping. 2015;28(5):576-86. https://doi. org/10.1080/10615806.2014.987666.

45. Nestor BA, Cheek SM, Liu RT. Ethnic and racial differences in mental health service utilization for suicidal ideation and behavior in a nationally representative sample of adolescents. J Affect Disord. 2016 Sep 15;202:197-202. https://doi.org/10.1016/j.jad. 2016.05.021.

46. Liu CH, Stevens C, Wong SHM, Yasui M, Chen JA. The prevalence and predictors of mental health diagnoses and suicide among U.S. college students: implications for addressing disparities in service use. Depress Anxiety. 2019 Jan;36(1):8-17. https://doi.org/10. 1002/da.22830.

47. DeFreitas SC, Crone T, DeLeon M, Ajayi A. Perceived and personal mental health stigma in Latino and African American college students. Front Public Health. 2018 Feb 26;6:49. doi: https://doi. org/10.3389/fpubh.2018.00049. This study emphasizes the salience of stigma as a barrier to mental health utilization among minority students, suggesting the need to address stigma among minority college students in particular.

48. Rein BA, McNeil DW, Hayes AR, Hawkins TA, Ng HM, Yura CA. Evaluation of an avatar-based training program to promote suicide prevention awareness in a college setting. J Am Coll Heal. 2018 Jul;66(5):401-11. https://doi.org/10.1080/07448481.2018. 1432626.

49. Coleman D, Black N, Ng J, Blumenthal E. Kognito's avatar-based suicide prevention training for college students: results of a randomized controlled trial and a naturalistic evaluation. Suicide Life Threat Behav. 2019 Dec;49(6):1735-45. https://doi.org/10.1111/ sltb. 12550 .

50. Toscos T, Carpenter M, Drouin M, Roebuck A, Kerrigan C, Mirro M. College students' experiences with, and willingness to use, different types of telemental health resources: do gender, depression/ anxiety, or stress levels matter? Telemed J E Health. 2018 Dec;24(12):998-1005. https://doi.org/10.1089/tmj.2017.0243.

51. Bird MD, Chow GM, Yang Y. College students' attitudes, stigma, and intentions toward seeking online and face-to-face counseling. J Clin Psychol. 2018 May 23;76(9):1775-90. https://doi.org/10. 1002/jocc. 12141.

52. Palmer KM. Undergraduate college students' attitudes about internet-based mental health interventions. Vol. 76, Dissertation Abstracts International: Section B: The Sciences and Engineering. ProQuest Information \& Learning. 2016; 76(11-B(E)). http:// search.ebscohost.com.proxy.lib.umich.edu/login.aspx?direct= true $\& \mathrm{db}=$ psyh \&AN=2016-17135-069\&site=ehost-live \&scope $=$ site.

53. Crosby Budinger M, Cwik MF, Riddle MA. Awareness, attitudes, and use of crisis hotlines among youth at-risk for suicide. Suicide Life Threat Behav. 2015 Apr;45(2):192-8. https://doi.org/10.1111/ sltb.12112

54. Lungu A, Sun M. Time for a change: college students' preference for technology-mediated versus face-to-face help for emotional distress. Telemed J E Health. 2016 Dec;22(12):991-1000. https://doi. org/10.1089/tmj.2015.0214.
55. Ruppel EK, McKinley CJ. Social support and social anxiety in use and perceptions of online mental health resources: exploring social compensation and enhancement. Cyberpsychol Behav Soc Netw. 2015 Aug;18(8):462-7. https://doi.org/10.1089/cyber.2014.0652.

56. Hedman-Robertson AS. Undergraduate students' exposure, knowledge, utilization, and intended use of the national suicide prevention lifeline. Crisis. 2018 Mar;39(2):110-8. https://doi.org/10.1027/ 0227-5910/a000480.

57. Kern A, Hong V, Song J, Lipson SK, Eisenberg D. Mental health apps in a college setting: openness, usage, and attitudes. Mhealth. 2018 Jun 30;4:20. doi: https://doi.org/10.21037/mhealth.2018.06. 01 . This is one of the most recent studies directly surveying students on their openness to.

58. Bernstein MH, Stein LAR, Neighbors C, Suffoletto B, Carey KB, Ferszt $\mathrm{G}$, et al. A text message intervention to reduce 21 st birthday alcohol consumption: evaluation of a two-group randomized controlled trial. Psychol Addict Behav. 2018 Mar;32(2):149-61. https://doi.org/10.1037/adb0000342.

59. Bedford LA, Dietch JR, Taylor DJ, Boals A, Zayfert C. Computerguided problem-solving treatment for depression, PTSD, and insomnia symptoms in student veterans: a pilot randomized controlled trial. Behav Ther. 2018 Dec;49(5):756-67. https://doi.org/ 10.1016/j.beth.2017.11.010.

60. Berkout OV, Gross AM. Barriers and opportunities: examining attitudes toward traditional and mobile health services in a nonclinical sample of non-Hispanic White and Latino/a undergraduates. J Technol Behav Sci. 2018;3:1-6.

61. Glowacki EM, Kirtz S, Hughes Wagner J, Cance JD, Barrera D, Bernhardt JM. HealthyhornsTXT: a text-messaging program to promote college student health and wellness. Health Promot Pract. 2018 Nov;19(6):844-55. https://doi.org/10.1177/ 1524839917754089 .

62. Gilbertson RJ, Norton TR, Beery SH, Lee KR. Web-based alcohol intervention in first-year college students: efficacy of full-program administration prior to second semester. Subst Use Misuse. 2018 May 12;53(6):1021-9. https://doi.org/10.1080/10826084.2017. 1392979.

63. Moffitt-Carney KM, Duncan AB. Evaluation of a mindfulness based mobile application with college students: a pilot study. J Am College Health. 2019:1-7. https://doi.org/10.1080/07448481. 2019.1661420.

64. College counseling from a distance: deciding whether and when to engage in telemental health services. Higher Education Mental Health Alliance. http://hemha.org/wp-content/uploads/2018/04/ HEMHA-Distance-Counseling_FINAL.pdf. Accessed December 2, 2020. This comprehensive guide created by experts in TMH offers an outline of the potential benefits, drawbacks, and legal and ethical concerns of TMH for college students.

65. Wesley A. NASPA policy and practice series: strategies for addressing mental health support on campus. NASPA Research and Policy Institute. 2019 May; https://www.naspa.org/images/uploads/ main/NASPA_Policy_and_Practice_Issue_4_Mental_Health DOWNLOAD.pdf. .

66. National College Health Assessment III Codebook. American College Health Association. 2020 Aug. https://www.acha.org/ documents/NCHA/ACHA-NCHAIIIFall2020Codebook8_31_20. pdf. .

Publisher's Note Springer Nature remains neutral with regard to jurisdictional claims in published maps and institutional affiliations. 